Sournals
ONTERNATIONAL JOURNAL OF
ORGANIZATIONAL LEADERSHIP $\begin{gathered}\text { INDUSTRIAL } \\ \text { MANAGEMENT } \\ \text { INSTITUTE }\end{gathered}$

\title{
Implementing learning organization components in Ardabil Regional Water Company based on Marquardt systematic model
}

\author{
Shahram Mirzaie Daryani ${ }^{1,2}$, Azadeh Zirak ${ }^{* 1,2}$ \\ ${ }^{1}$ Department of Management, Ardabil Science and Research Branch, Islamic Azad University, Ardabil, Iran \\ 2 Department of Management, Ardabil Branch, Islamic Azad University, Ardabil, Iran
}

\begin{abstract}
Keywords:

This main purpose of this study was to survey the implementation of learning organization characteristics based on Marquardt systematic model in Ardabil Regional Water Company.

Learning Organization, Organizational Learning Management, Knowledgebased Learning System

Correspondence:

za_zirak313@yahoo.com Two hundred and four staff (164 employees and 40 authorities) participated in the study. For data collection Marquardt questionnaire was used which its validity and reliability had been confirmed. The results of the data analysis showed that learning organization characteristics were used more than average level in some subsystems of Marquardt model and there was a significant difference between current position and excellent position based on learning organization characteristic application. The results of this study can be used to improve work processes of organizations and institutions.
\end{abstract}

(C)AIMI Journals

\section{Introduction}

Over the last decade, there have been profound social, economic, political, and cultural transformations and organizations have used their best endeavor to create active frameworks for moving towards learning organizations. Following this, organizations learn that the interaction between organization and its environment induces individuals to identify the 
problematic situations which need knowledge for solving problems. In fact, they consider learning as a tool to enhance the performance and adapt to environmental changes. This means that the organizations' rates of learning must be greater than the rate of environmental changes in order to survive them and this issue further magnifies the importance of organizational learning (Fathi \& Strichman, 2010).

The most common problem that organizations face these days is gradually shifting from individual learning to organizational learning. For such shifting, individual knowledge should be defined and operationalized within organizational operating system to boost its functions (Revilla \& Sanchez, 2003). This knowledge should be related and visualized the daily organizational performances. This job-related knowledge comes from other workers or learning on their own job rather than employment-related courses. Employees learn informally this knowledge from their colleagues when they work cooperatively and speak about their most influential to least influential work experiences. The outputs of pioneer learning organization are rich products or services which are distributed in today's competitive market. Hence, the main aim of this study is to describe the concept of learning organization to determine its main characteristics which influence the organizational performance. The lack of attention given to the possible influence of this matter in the previous studies has highlighted a significant issue that requires further investigation.

\section{Organizational Learning}

Historically, the concept of organizational learning has received increasing attention from scholars in the management and organizational theory literature. Organizational learning has been developed before the learning organization. The research about organizational learning has paved the way for the formation of learning organization theory. According to Gephart and Marsick (1996), a learning organization has a great capacity to learn, adapt, and change into its culture. It is a concept used to describe certain kinds of activities that take place in an organization (Rahnavard, 2000).

Organizational learning is a term introduced in the 1978s by Chris Argyris and Donald Schön. Chris Argyris (1993) was interested in producing knowledge that is actionable (producing applicable knowledge). In his point of view, it was the time to avoid spiritual instructions and inductions and move towards the executive jobs and the practical advice. Organizational learning is considered as key aspect in promoting innovation and creativity. It 
is a process of detecting and correcting errors, mistakes, and their modifications. It is based upon past experiences and awarenesses of past events and has occurred through shared insight, knowledge, and mental models. Therefore, organizational learning is a process of acquiring knowledge and improving the re-utilization of knowledge over the time (Fulmer \& Keys, 1998). The terms such as organizational learning and learning organization are not synonymous. Organizational learning means learning individuals in group or intergroup relations and learning organization means learning system as a whole. Ang and Joseph (1996) contrasted organizational learning and learning organization in terms of process versus structure. Learning organization builds learning in an organization; on the contrary, organizational learning is a significant organizational behavior that actually occurs in organizations. Learning organization is considered as an existence while organizational learning is seen as a process or an action-reaction set. Learning provides foundation for professional development and enduring human resource development which organizations can use to provide more creativity, upper-level customer service, and more profit. Learning is the key factor in the competitive environment and uncertainty of market. Learning should be related to the essential skills of business and expected results of managers, customers, partners, and beneficiaries. These people will evaluate the efficiency of training courses not just through passing the courses or course attendance but also through improving effectiveness of business performances. In these organizations, the business performances such as talent absorption, communication management, leadership quality, manufacturing cycle time reduction, production speed of new products, synthesis (modulation), risk management, following the law, efficiency of employees performance, and customer and employee satisfaction are called learning (Manville, 2001). From experts’ point of view, organizational learning is the most important ability of an organization to make changes along environmental changes (Conner, 1992, 1993).

\section{Learning Organization}

Scholars have proposed a variety of definitions of organizational learning up to now. This contradiction among scholars over this concept led Garvin (2000) to argue that there is no single clear definition of learning organization. He defined learning organization as organizational skill and ability for acquiring knowledge and modifying behavior to reflect new knowledge and insights. He also believed that organizational learning is a logical 
consequence of active social participation that has happened in the realm of organizational development. In learning organization, learning how to learn is considered more valuable than any other kinds of learning and creativity and innovation become more valuable than stability and compatibility. It is such an organization which constantly improves its abilities and capacities in order to guarantee a better future. In contrary to Sangeh (1990 a, b), Pearn, Roderick, and Mulrooney (1995) emphasized on the continuous ability of self-conveying. Self-conveying is the process of preparation for the continuous self-change and enhancing individual ability. This aim is only achieved when the importance of learning is known.

According to Garvin, Edmonson, and Gino (2008), organizational learning is an organization that provides a supportive environment for learning security including psychological security, welcoming the differences, admitting new concepts, learning processes, namely creation, collection, interpretation and dispersion, and learningencouraging organizational managers. Learning organization functions improve and recover through awareness and perception. It is claimed that an organization is learning one when it can change and improve the domain of potential behaviors through communication process. Organizations shift to learning and knowledge creating organizations when they practically apply their experiences. Marquardt (2002) viewed learning organization as an organization which learns strongly and collectively and regularly changes itself in order to use, gather, and mange information better towards the goals of organizational setting. Learning organization foster an environment where individuals increase their own abilities for creation of what is being asked. Senge (1992) believed that it is a place in which new patterns of thinking are raised and collective thoughts are spread and individuals continuously learn how to learn together. It is understandable through different perspectives regarding learning organizations that these organizations carry the recognition of the problem and the solution within themselves. The organizations of this type represent a flexible and dynamic network of individuals and have positive interactions with their surrounding environment. They are selfbalanced and self-control organizations. Reciprocal learning is common in organizational level between management and staff. Reciprocal learning is the driving engine behind group learning and team-based learning in accordance with the requirements of their time and changes and corrections in organizational and environmental needs. Given learning organization, generally, there are two fundamental frameworks in academic area. These two frameworks are American conceptual model which was introduced by Peter Senge and European model which was presented by several outstanding theorists. Inspired by these two 
frameworks, other learning organization specialists and experts try to extend and expand learning organization in different dimensions. Table 1 presents different perspectives of learning organization.

Table 1

Different Perspectives of Learning Organization

\begin{tabular}{|c|c|}
\hline Perspective & Components of Learning Organization \\
\hline $\begin{array}{l}\text { Pedler, Burgoyne, and } \\
\text { Boydell (1991) }\end{array}$ & $\begin{array}{l}\text { A learning approach to strategy, participative policy making, informing, formative accountability and } \\
\text { control, internal exchanges, reward flexibility, enabling structure, intercompany learning, boundary workers } \\
\text { as environmental scanners, learning climate, and self-development opportunities for everyone }\end{array}$ \\
\hline Peter Senge (1990 a) & $\begin{array}{l}\text { Systems thinking, Personal mastery, improving mental models, building a shared vision (BSV), team } \\
\text { learning }\end{array}$ \\
\hline Garvin (1993) & Ability to create, acquire, and transfer knowledge \\
\hline Marquardt (1996) & Collective learning, and permanent organizational changes \\
\hline $\begin{array}{l}\text { Gephardt and Marsick } \\
\text { (1996) }\end{array}$ & $\begin{array}{l}\text { Continuous learning at the systems level, knowledge generation and sharing, system and critical thinking, a } \\
\text { culture of learning, being people-centered, a spirit of flexibility and experimentation }\end{array}$ \\
\hline $\begin{array}{l}\text { Watkins and Marsick } \\
(1993,2004)\end{array}$ & $\begin{array}{l}\text { Creating continuous learning opportunities, promoting inquiry and dialogue, encouraging collaboration and } \\
\text { team learning, creating systems to capture and share learning, empowering people toward a collective vision, } \\
\text { connecting the organization to its environment, and providing strategic leadership for learning }\end{array}$ \\
\hline $\begin{array}{l}\text { Argyris and Schön } \\
(1978,1996)\end{array}$ & Fusion of organizational learning and learning theories \\
\hline Mumford (1961) & A natural environment for promoting sustainable development of existing behaviors \\
\hline $\begin{array}{l}\text { Harrison and Dourish } \\
\text { (1996) }\end{array}$ & A culture of learning, collaborative learning process, and systems thinking \\
\hline
\end{tabular}

The organizations cooperate together rather than merely constrain rivalry and they try hard to find the best way for learning and environmental compatibility. In this kind of organization, everything can determine the strategy and everywhere it can be determined in a way that people feel belonging to a thing or place. Also, organizations can be changed to a place that we can provide a communication network where the growth and community development would be achieved there. Such kind of organization provides a proper situation for loving and giving respect to others that the learning organization's members use it for gaining experience through making repetitious mistakes and tasting the bitter taste of defeat which finally leads to learning more. Individuals learn that as a member of a team or a greater community they can gain valuable experiences. In learning organizations, the activities that could affect the environment of an organization which cause controversies among employees should not be conducted (Daft, 2012). 


\section{Learning Organization Models}

Since the early 1990s, various theories about learning organizations have been proposed by organizational theorists. Furthermore, some scholars try to check the concept of learning organizations practically besides the theoretical discussions through designing conceptual models and their implications in the real environment of organizations. One of these models is the INVEST model of organizational learning which is used for evaluating learning organization. Pearn, Raderick, and Mulrooney (1995) proposed a six factor model of learning organizations. It consists of inspired learners, nurturing culture, vision of the future, enhanced learning, supportive management, and transforming structures.

The second model, Behnami's organizational learning model (2005), represented an organizational learning model based on three factors. Enablers who generally include strategies, policies, leadership (management), people management (human resources and information technology processes) are the first factor. The second factor is environment which says that if all enablers are available but there is not a necessary environment for the growth of learning organization, all of those efforts will be less effective or ineffective. This factor involves levels, types, and skills of learning. The third factor is the results which refer to enablers' utilization and creating the required environment as well as mechanisms and organizational learning systems.

The third model, Seajou's mixed learning flow (2001), presented a model in which both individual and collective learning was shown. He said that the feedback from initiatives and operations can be a factor of individual and organizational learning. Policies and ideas enrich operations and make them more productive. Precisely speaking, when these models mix, they provide a final integrated model of learning. This model shows dynamic relationship among organizational operations, individual actions, organizational policies, and people's visions.

The main idea of the model is based on the fact that no action is possible without learning and no learning is possible without practice. A learning organization should essentially pay attention to such blocks and interaction of these pillars. In this model, we see four processes of contribution, conduct, management, and learning (Seajou, 2001).

Putting a human head on the biological (open-system) model, Garvin (2000) extended the open system model of organizations. He believed that organizational learning, just like human learning, consisted of three stages, namely cognition (learning new concepts), behavior (developing new skills and abilities), and performance (actually getting something done). All the stages are necessary to bridge the gap out between theory and practice. Five 
organizational skills, i.e., solving problems, experimenting, learning from own experience or history, learning from others, and implementing and transmitting are needed to turn new ideas into improved organizational performance if today's organizations want to truly succeed (Garvin, 2000).

According to Marquardt systemic model, four influential factors including people, technology, knowledge and organization in the role of subsystems, and learning process in the role of main system were recognized. Each aspect is analyzed based on a series of indices in terms of their roles in the main subsystem of learning. In the subsystem of people, managers, employees, customers, suppliers, sellers, contractors, partners, and society are studied. In organization subsystem, perspective, culture, structure, and strategy are studied. In technology subsystem, knowledge management, accessibility to information, and information exchange are investigated. Finally, in knowledge subsystem, knowledge generation and knowledge management, storing, analyzing, and exploring data are studied.

Marquardt (2002) asserted that an organization becomes learning when new behaviors are rooted in social norms and common values. Moreover, he believed that it is necessary to implement the following ten strategies to build learning subsystem, namely develop modular and reusable learning plans, increase people's capability on learning how to learn, develop organizational dialogue, design development plans based on employees' capability, design self- grooming plans, execute systemic learning skills, encourage and execute systemic thinking approach, use scenario planning for learning, expand domestic and universal intercultural mindsets and learning, and finally increase employees' intervention and contribution. Figure 1 depicts the learning organizational systematic model based on Marquardt model.

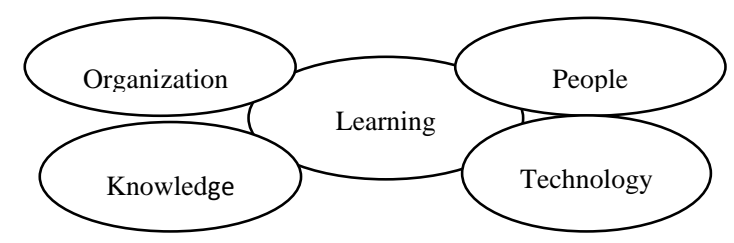

Figure 1. Learning organizational systematic model based on Marquardt systematic model

\section{Measuring the Process of Organizational Learning}

Managers have long known that if they cannot measure processes, actions, and improvements, they cannot manage. This maxim is true for learning as well as any other 
corporate objectives. Traditionally, the solution for measuring learning in organization was learning curves and manufacturing progress functions. Both concepts date back to the 1920s and 1930s. Later studies expanded the focus, looking at total manufacturing costs and the impact of experience in other industries that their results were proposed on the learning curves. Drawing on the logic of experience curves, they argued that as industries grew and their total production increased, the costs and prices of their productions dropped by predictable amounts.

Although both learning and experience curves are still widely used these days, Garvin (2000) claimed that these curves are not sufficient for companies hoping to become learning organizations. He argued that the focus of these curves is only on a single indicator of output such as the price or cost of product and ignore learning that influences other competitive variables, like new product introductions, quality, and delivery.

\section{Key Factors in Evaluating of Learning Organization}

The executive administrators should respond to each of the following questions such as what a learning organization is, what the learning organization mechanisms are in their organizations, how their organizations go about it and practice the self-organization and new management, and what the reasons for building the learning organization are if they want to evaluate learning in these organizations (Sobhaninezhad, Shahei, \& Youzbashi, 2007). The dimension of the learning organization questionnaire (DLOQ) is the most comprehensive questionnaire which was provided to measure seven dimensions of learning by Watkins and Marsick (2003, 2004). This questionnaire enables us to think about how our organization supports and uses learning at an individual, team, organizational, and macro level. These dimensions include continuous learning, empowerment, peer collaboration and learning, embedded systems, systems connections, dialogue and inquiry, and providing leadership.

\section{Related Empirical Studies}

The comparative analysis of universities in Thailand revealed that these universities regarding level of learnability of components of knowledge management were at desirable level compared to other components of learning organization (Ling Hsieh, 2005). Selden (1998) evaluated the characteristics of learning organization with knowledge and financial performance in family run firms. The positive relationship between the learning organizations characteristics and perceived financial performance is indicated as significant in his study. 
Hoshvand, Mirzaie Daryani, and Aali (2013) conducted a study on effects of organizational learning in Islamic Azad University in Tabriz branch based on the Armstrong-Foley model. They presented the model of learning based on Armstrong-Foley model to change Azad University of Tabriz into a learning organization.

\section{Research Hypotheses}

Concerns about the function and effectiveness of learning organization form the basis for the research questions of this study. As a result, the following research hypotheses are hoped to be answered in this study:

$\mathrm{H}_{1}$. Ardabil Regional Water Company's situation is more than average level in the dynamic learning subsystem.

$\mathrm{H}_{2}$. Ardabil Regional Water Company's situation is more than average level in the organizational transformation subsystem.

$\mathrm{H}_{3}$. Ardabil Regional Water Company's situation is more than average level in the subsystem of strengthening the people/individuals.

$\mathrm{H}_{4}$. Ardabil Regional Water Company's situation is more than average level in the subsystem of knowledge management.

$\mathrm{H}_{5}$. Ardabil Regional Water Company's situation is more than average level in the subsystem of using technology.

\section{Method}

In total, 204 of Water Company's employees and authorities (40 authorities and 164 employees) participated in this study. A questionnaire developed by Marquardt (2002) was used to measure dimensions of learning organization. It was organized into four distinct categories which measure respondents' frequency of actual use by means of a five-point Likert scale. It enables managers and authorities to think about how their organizations support and use learning at an individual, team, and organization level. This standardized questionnaire is commonly used in large field studies. The internal consistency of the questionnaire also was determined through Cronbach's alpha coefficient which was 0.96. To confirm the content validity of the questionnaire, the researcher asked several experts in the field to rate the instrument's efficacy in terms of how effectively it measures learning organization. 


\section{Results}

In order to answer the first hypothesis and establish the homogeneity of both authorities and employees groups in terms of dynamic learning, an independent samples t-test was performed to compare questionnaire gain scores of the authorities and employees groups.

Table 2

Results of Descriptive Statistics of Dynamic Learning

\begin{tabular}{lccc}
\hline Group & $\mathrm{N}$ & Mean & SD \\
\hline Authorities & 40 & 4.27 & 0.51 \\
Employees & 164 & 4.29 & 0.60 \\
\hline
\end{tabular}

Table 2 displays that authorities group and employees group were found to be at similar levels of dynamic learning because their means were similar (authorities group $=4.27$, employees group $=4.29$ ). Furthermore, an independent samples t-test was run to compare the dynamic learning scores for both groups to establish whether these two means were statistically significant or not. The independent samples t-test evaluated whether the mean value of the test variable, i.e., dynamic learning for the authorities group differs significantly from the mean value of the test variable for the employees group. Table 3 illustrates the results of the questionnaire for the authorities and employees groups.

Table 3

Independent Samples T-test for the Total Dynamic Learning Sub-system

\begin{tabular}{ccccccc}
\hline Variable & \multicolumn{7}{c}{ T-test for Equality of Means } \\
\cline { 2 - 5 } $\begin{array}{c}\text { (Dynamic } \\
\text { Learning) }\end{array}$ & $\begin{array}{c}\text { Sig. } \\
\text { (2-tailed) }\end{array}$ & $\mathrm{t}$ & $\mathrm{df}$ & $\begin{array}{c}\text { Mean } \\
\text { Differences }\end{array}$ & \multicolumn{2}{c}{ 95\% Confidence Interval of the Difference } \\
\hline Authorities & 0.00 & 9.55 & 39 & 1.27 & 0.99 & Lower \\
Employees & 0.00 & 48.93 & 163 & 1.29 & 1.23 & 1.54 \\
\hline
\end{tabular}

As shown in Table 3, the difference between the authorities group ( $\mathrm{t}(39)=9.55, p=0.00$ $<0.05$ ) and employees group ( $(163)=48.93, p=0.00<0.05)$ was considered to be statistically significant. The $p$-value less than the significance level $(p<0.05)$ means that the variances for the two groups were not the same. The magnitude of the differences in the means for both groups were $\mathrm{MD}$ (authorities) $=1.27$ and $\mathrm{MD}$ (employees) $=1.29$ respectively which were positive quantities. There was a significant difference in the mean scores on the dependent variable for each of the two groups. That is, the participants' dynamic learning sub-system in both groups was more than the average level. Based on these data, the first hypothesis which stated that the Ardabil Regional Water Company's situation is more than average level in the dynamic learning subsystem was confirmed. 
In order to test the second hypothesis, descriptive statistics were used at the onset of the study. The descriptive statistics are illustrated in Table 4. As the descriptive data in Table 4 shows, there was a similarity in the mean scores of the authorities group and employees group $\left(\mathrm{M}_{\text {(authorities) }}=2.78, \mathrm{M}_{\text {(employees) }}=2.86\right)$. In order to see whether organizational transformation has caused a significant difference between the authorities and the employees groups, the researcher ran an independent sample t-test.

Table 4

Results of Descriptive Statistics of Organizational Transformation

\begin{tabular}{lccc}
\hline Group & $\mathrm{N}$ & Mean & SD \\
\hline Authorities & 40 & 2.78 & 0.61 \\
Employees & 164 & 2.86 & 0.52 \\
\hline
\end{tabular}

Table 5 illustrates the results of the questionnaire for the authorities and employee groups. As shown in Table 5, the difference between the authorities group $(\mathrm{t}(39)=-1.37, p=0.13>$ 0.05 ) and the employees group (t $(163)=-1.56, p=0.14>0.05)$ was not statistically significant. The $p$-values from t-test were 0.13 and 0.14 which were more than 0.05 , therefore, it can be concluded that the test was meaningless and there was no significant difference in Ardabil Regional Water Company's situation according to the subsystem of organizational transformation. Based on these data, the second hypothesis which is stated that Ardabil Regional Water Company’s situation is more than average level in the organizational transformation subsystem was rejected.

Table 5

Independent Sample T-test for the Total Organizational Transformation Sub-system

\begin{tabular}{cccccccr}
\hline $\begin{array}{c}\text { Variable } \\
\text { (Dynamic } \\
\text { Learning) }\end{array}$ & \multicolumn{7}{c}{ T-test for Equality of Means } \\
\cline { 2 - 7 } \cline { 5 - 7 } & Sig. & $\mathrm{t}$ & $\mathrm{df}$ & $\begin{array}{c}\text { Mean } \\
\text { Differences }\end{array}$ & 95\% Confidence Interval of the Difference \\
\hline Authorities & 0.13 & -1.37 & 39 & -0.22 & -0.27 & Upper \\
Employees & 0.14 & -1.56 & 163 & -0.13 & -0.20 & 0.04 \\
\hline
\end{tabular}

Table 6 shows the descriptive statistics of the authorities and employees groups to test the third hypothesis. The mean score for authorities' group scores was 2.55 and the employees group's mean was 2.48 .

Table 6

Results of Descriptive Statistics of Strengthening Individuals

\begin{tabular}{lccc}
\hline Group & $\mathrm{N}$ & Mean & SD \\
\hline Authorities & 40 & 3.82 & 0.70 \\
Employees & 164 & 3.84 & 0.56 \\
\hline
\end{tabular}

Table 7 illustrates the results of the questionnaire for the authorities and employees groups. As shown in this table, the difference between the authorities group ( $\mathrm{t}(39)=5.46, p$ 
$=0.00<0.05)$ and employees group $(\mathrm{t}(163)=28.02, p=0.00<0.05)$ was statistically significant.

Table 7

Independent Sample T-test for the Total Strengthening Individuals Sub-system

\begin{tabular}{|c|c|c|c|c|c|c|}
\hline \multirow{3}{*}{$\begin{array}{l}\text { Variable } \\
\text { (Dynamic } \\
\text { Learning) } \\
\end{array}$} & \multicolumn{6}{|c|}{ T-test for Equality of Means } \\
\hline & \multirow{2}{*}{$\begin{array}{c}\text { Sig. } \\
\text { (2-tailed) }\end{array}$} & \multirow[t]{2}{*}{$\mathrm{t}$} & \multirow[t]{2}{*}{$\mathrm{df}$} & \multirow{2}{*}{$\begin{array}{c}\text { Mean } \\
\text { Differences }\end{array}$} & \multicolumn{2}{|c|}{ 95\% Confidence Interval of the Difference } \\
\hline & & & & & Lower & Upper \\
\hline Authorities & 0.00 & 5.46 & 39 & 0.82 & 0.99 & 1.54 \\
\hline Employees & 0.00 & 28.02 & 163 & 0.84 & 0.89 & 0.78 \\
\hline
\end{tabular}

The magnitude of the differences in the means for both groups were $\mathrm{MD}$ (authorities) $=0.82$ and $\mathrm{MD}$ (employees) $=0.84$ respectively which were positive quantities. There was a significant difference in the mean scores on the dependent variable for each of the two groups. It means that the participants' strengthening individuals' sub-system in both groups was more than the average level. Based on these data, the third hypothesis which stated that Ardabil Regional Water Company's situation is more than average level in the strengthening individuals' subsystem was confirmed.

Before performing the main statistical test (independent samples t-test) to test the fourth hypothesis, descriptive results were obtained to achieve a general understanding of the differences between the means of the two groups, authorities and employees. Table 8 shows that the authorities group scores was 2.55 and the employees group's mean of questionnaire scores was 2.48 .

Table 8

Results of Descriptive Statistics of Knowledge Management

\begin{tabular}{lccc}
\hline Group & $\mathrm{N}$ & Mean & $\mathrm{SD}$ \\
\hline Authorities & 40 & 2.55 & 0.59 \\
Employees & 164 & 2.48 & 0.57 \\
\hline
\end{tabular}

In order to see whether the difference between the mean scores of the groups was meaningful or not, the researcher employed an independent samples t-test. Table 9 illustrates the results of the questionnaire for the authorities and employees groups. As shown in this table, the difference between the authorities group (t (39) $=-1.34, p=0.11>0.05$ ) and employees group (t $(163)=-2.56, p=0.38>0.05)$ was statistically significant. The $p$-value more than significance level (0.05) indicating that the variances for the two groups were the same. There was a significant difference in the mean scores on the dependent variable for each of the two groups. That is, the participants' knowledge management sub-system in both groups was more than the average level. Accordingly, the fourth hypothesis which stated that 
Ardabil Regional Water Company's situation is more than average level in the dynamic learning subsystem was rejected.

Table 9

Independent Sample T-test for the Total Knowledge Management Sub-system

\begin{tabular}{|c|c|c|c|c|c|c|}
\hline \multirow{3}{*}{$\begin{array}{c}\text { Variable } \\
\text { (Dynamic } \\
\text { Learning) }\end{array}$} & \multicolumn{6}{|c|}{ T-test for Equality of Means } \\
\hline & \multirow{2}{*}{$\begin{array}{c}\text { Sig. } \\
\text { (2-tailed) }\end{array}$} & \multirow[t]{2}{*}{$\mathrm{t}$} & \multirow[t]{2}{*}{$\mathrm{df}$} & \multirow{2}{*}{$\begin{array}{c}\text { Mean } \\
\text { Differences }\end{array}$} & \multicolumn{2}{|c|}{ 95\% Confidence Interval of the Difference } \\
\hline & & & & & Lower & Upper \\
\hline Authorities & 0.11 & -1.34 & 39 & -0.45 & -0.17 & 0.09 \\
\hline Employees & 0.38 & -2.56 & 163 & -0.52 & -0.17 & 0.07 \\
\hline
\end{tabular}

In order to assess the effect of using technology on the participants' learning organization, an independent samples t-test was conducted. Table 10 shows descriptive statistics of the authorities and employees groups. As Table 10 clearly represents, the mean scores of the authorities and employees groups were 3.97 and 4.05 respectively.

Table 10

Results of Descriptive Statistics of Using Technology

\begin{tabular}{lccc}
\hline Group & $\mathrm{N}$ & Mean & $\mathrm{SD}$ \\
\hline Authorities & 40 & 3.97 & 0.59 \\
Employees & 164 & 4.05 & 0.57 \\
\hline
\end{tabular}

Table 11 illustrates the results of t-test for the authorities and employees groups. The difference between the authorities group $(\mathrm{t}(39)=7.20, p=0.00<0.05)$ and employees group $(\mathrm{t}(163)=40.40, p=0.00<0.05)$ was considered to be statistically significant. Therefore, as data analysis indicated, the fifth hypothesis which stated that Ardabil Regional Water Company's situation is more than average level in the using technology subsystem was confirmed.

Table 11

Independent Sample T-test the Total Using Technology Sub-system

\begin{tabular}{lccccccc}
\hline Variable & \multicolumn{7}{c}{ T-test for Equality of Means } \\
\cline { 2 - 5 } $\begin{array}{l}\text { (Dynamic } \\
\text { Learning) }\end{array}$ & $\begin{array}{c}\text { Sig. } \\
\text { (2-tailed) }\end{array}$ & $\mathrm{t}$ & $\mathrm{df}$ & $\begin{array}{c}\text { Mean } \\
\text { Differences }\end{array}$ & \multicolumn{2}{c}{ 95\% Confidence Interval of the Difference } \\
\hline Authorities & 0.00 & 7.20 & 39 & 0.97 & Lower & Upper \\
Employees & 0.00 & 40.40 & 163 & 1.05 & 1.00 & 0.09 \\
\hline
\end{tabular}

\section{Discussion and Conclusion}

The main purpose of the present study was to survey the implementation of learning organization characteristics based on Marquardt systematic model in Ardabil Regional Water 
Company. The findings of the study revealed that Ardabil Regional Water Company placed in a fairly good position regarding learning organization's characteristics. The major finding of this study was that Ardabil Regional Water Company was in suitable condition (more than the average level) considering to its dynamic learning, strengthening or enforcing the people/individual, and using technology subsystems, while the other two subsystems, i.e., organizational transformation and the knowledge management subsystems made a negative significant difference, i.e., lower than the average level in the development of learning organization characteristics for both authorities and employers groups. According to the findings of the study, we can implement the characteristics of a learning organization in mentioned dimensions in Ardabil Regional Water Company by providing appropriate ground for improving these subsystems which guide this company to achieve these characteristics. The under study organization did not show all five subsystems simultaneously, and therefore it should take measures to move towards organizational learning and changing into learning organization by using its strengths and strengthening its weaknesses because these five subsystems create a learning organization by continuously interacting with each other.

Learning is not only for learning but also is necessary for organizational success and development. If there were not any learning, the organizations would encounter with enormous rework costs, inefficiencies, and waste of resources, and skills and they would lose their self-confidence and income gradually because of the lack of innovation. However, organizational efficiency will help increase the productivity of their work force, develop, and change them to organizational capitals by becoming committed to the long-life learning and increasing organizational enthusiasm and commitment.

The current study also has several limitations. The very first limitation of the study relates to using only Ardabil Regional Water Company's employees and authorities and excluding other state and private organizations. Second, the sample size could be expanded, as data collected from a larger number of companies will permit more powerful hypothesis testing. This study was based on self-report data and so the findings may be biased by common method variance and spurious cause/effect inferences. Common method variance is a potential problem whenever data are collected from a single source, i.e., questionnaire. The major inherent drawback of this technique is that it does not provide the researcher with any kind of sound foundation for making general inferences about the population from which this sample was drawn or the whole population of different organizations. In order to strengthen and back up the findings and conclusions in this study, it is essential to implement further 
research in this regard. A study of other factors would provide a fruitful insight into the development of learning organization. It would also be useful to study the interaction effect of these five subsystems and its impact on learning organization which was not dealt with in this study.

\section{References}

Ang, S. A., \& Joseph, A. D. (1996). Organizational learning and the learning organization: Triggering events, processes, and structures. Proceedings of the Academy of Management meeting, Cincinnati, $\mathrm{OH}$.

Argyris, C. (1993). Knowledge for action: A guide to overcoming barriers to organizational change. San Francisco, CA: Jossey-Bass.

Argyris, C., \& Schön, D. (1978). Organizational learning: A theory of action perspective. Reading, Mass: Addison Wesley.

Argyris, C., \& Schön, D. A. (1996). Organizational learning II: Theory, method, and practice. Reading, MA: AddisonWesley.

Behnami, J. (2005). Organizational learning. Tadbir Journal, 161, 19-25.

Conner, D. R. (1992). Managing at the speed of change: How resilient managers succeed and prosper where others fail. New York: Villard Books.

Conner, D. R. (1993). Managing at the speed of change. New York: Villard Books.

Daft, R. L. (2012). Organization theory and design. Mason, U.S.: Cengage Learning.

Fathi, R., \& Strichman, N. (2010). Adaptive capacity and social change: A conceptual framework. Organizational learning and long-term stability. New England Journal of Public Policy, 23(1), 103-111.

Fulmer, R. M., \& Keys, J. B. (1998). A conversation with Chris Argyris: The father of organizational learning. Organizational Dynamics, 27(2), 21-31.

Garvin, D. A. (1993). Building a learning organization. Harward Bussiness Review, 71(4), 78-91.

Garvin, D. A. (2000). Learning in action: A guide to putting the learning organization to work. Boston: Harvard Business School Press.

Garvin, D. A., Edmondson, A. C., \& Gino, F. (2008). Is yours a learning organization? Harvard Business Review, 86(3), 109-116.

Gephart, M. A., \& Marsick, V. J. (1996). Learning organizations come alive. Training \& Development, 50(12), 35-45.

Harrison, S., \& Dourish, P. (1996). Replacing space: The roles of place and space in collaborative systems. Proceedings of ACM Conference on Computer Supported Cooperative Work (CSCW), Boston, USA.

Hoshvand, M., Mirzaie Daryani, S., \& Aali, S. (2013). Designing of learning organization model case study: Islamic Azad University, Tabriz branch. Journal of Basic \& Applied Scientific Research, 3(9), 253-261.

Ling Hsieh, H. (2005). Shaping university as learning organizations in Taiwan: A comparative study on comprehensive and technology universities. World Transactions on Engineering \& Technology Education, 2, 245-248.

Manville, B. (2001). Learning in the new economy. Leader to leader, 20, 36-45.

Marquardt, M. J. (1996). Building the learning organization. New York: McGraw- Hill.

Marquardt, M. J. (2002). Building the learning organization: Mastering the five elements for corporate learning. Palo Alto: Davies-Black Press.

Mumford, L. (1961). The city in history: Its origins, its transformations, and its prospects. New York: Harcourt Brace.

Pearn, M., Roderick, C., \& Mulrooney, C. (1995). Learning organization in practice. England: McGraw- Hill.

Pedler, M., Burgoyne, J., \& Boydell, T. (1991). The learning company: A strategy for sustainable development. New York: McGraw-Hill. 
Rahnavard, F. (2000). Organizational learning and learning organization. Journal of Public Administration, 43, $16-25$.

Revilla, E., \& Sanchez-Alarcos, J. (2003). Organizational evolution and semiotics in complex environments: The case of the aerial safety. Paper presented at the Sixth Organizational Semiotic Conference, UK.

Seajou, I. (2001). How organizations learn. Journal of Technology Management, 89(2), 139-155.

Selden, G. (1998). Dimensions of the learning organization in family-run businesses (Unpublished doctoral dissertation).University of Georgia, Athens.

Senge, P. M. (1990a). The fifth discipline: The art and practice of the learning organization. New York: Doubleday \& Company, Inc.

Senge, P. M. (1990b). The leader’s new work: Building learning organizations. Sloan Management Review, 31(1), 7-23.

Senge, P. M. (1992). Building learning organizations. The Journal for Quality \& Participation, 15(2), 30-38.

Sobhaninezhad, M., Shahei, B., \& Youzbashi, A. (2007). Learning organization. Tehran: Yastroun Publication.

Watkins, K. E., \& Marsick, V. J. (1993). Sculpting the learning organization. San Francisco, CA: Jossey-Bass.

Watkins, K. E., \& Marsick, V. J. (2003). Demonstrating the value of an organization's learning culture: The dimensions of the learning organization questionnaire. Advances in Developing Human Resources, 5(2), 132-151.

Watkins, K. E., \& Marsick, V. J. (2004). The construct of the learning organization: Dimensions, measurement, and validation. Journal of Human Resource Development Quarterly, 24(4), 33-45. 